\title{
Heterogeneity of neocortical cerebral blood flow deficits in dementia of the Alzheimer type: a [99m Tc]-d,l-HMPAO SPECT study
}

Gunhild Waldemar, Peter Bruhn, Mikael Kristensen, Anni Johnsen, Olaf B Paulson, Niels A Lassen surement of regional cerebral blood flow (rCBF), single photon emission computer tomography (SPECT) has become increasingly important in the clinical diagnosis of Alzheimer's disease and other dementia disorders. [ $\left.{ }^{99 \mathrm{~m}} \mathrm{Tc}\right]-d, l$-hexamethylpropyleneamineoxime (HMPAO) is a lipophilic radio-pharmaceutical tracer for measurement of rCBF with SPECT. ${ }^{1}$ After rapid conversion to a hydrophilic form it is retained in the brain for several hours, ${ }^{2}$ and with a brain dedicated SPECT system the axial and image plane resolution is close to $10 \mathrm{~mm}$ or finer. ${ }^{3}$ Most reports on SPECT studies with [99m $\mathrm{Tc}]-d, l-$ HMPAO in patients with a clinical diagnosis of Alzheimer's disease have concluded that Alzheimer's disease is associated with a rather specific rCBF pattern characterised primarily by bilateral reduction of $\mathrm{rCBF}$ in the posterior temporoparietal cortex..$^{-12}$ In many of these studies a visual analysis of the SPECT images was performed, or mean $\mathrm{rCBF}$ values were compared with rCBF data from control subjects. PET studies have suggested, however, that the topography of hypometabolism in the brain is more heterogenous, corresponding with the neuropsychological patterns of impairment. ${ }^{13-15}$ As function, metabolism, and blood flow of the brain are closely linked, it is assumed that patterns of hypoperfusion correspond closely to patterns of hypometabolism. The discrepancy between previous studies could be partly related to differences in selection of patients and control subjects and to differences in image analysis. In particular, interindividual heterogeneity of rCBF patterns may be overlooked in conventional group comparisons of mean regional $\mathrm{CBF}$ values.

The aim of this prospective [99m Tc]- $d, l$ HMPAO high resolution SPECT study was to investigate the topography of cerebral hypoperfusion in patients with a clinical diagnosis of probable Alzheimer's disease selected according to rigorous inclusion and exclusion criteria: our primary goal was to determine the topography of rCBF reduction (the rCBF pattern) in each patient according to the individual $\mathrm{rCBF}$ data and normal intervals for internal $\mathrm{rCBF}$ ratios, with reference to a number of predefined and simple rCBF patterns. We also aimed to analyse, by a factorial analysis of variance and conventional group comparisons, whether any region(s) had a disproportionate reduction of $\mathrm{rCBF}$ in the group of patients as a whole. Our third aim was to examine the relation between the $\mathrm{rCBF}$ 
patterns and the clinical characteristics of the patients, including age of onset, duration of disease, severity of dementia, and cortical atrophy on cranial CT.

\section{Patients and methods \\ PATIENTS}

In a prospective study on SPECT in dementia, 25 consecutive patients fulfilled the clinical criteria from the National Institute of Neurological and Communicative Disorders and Stroke and the Alzheimer's Disease and Related Disorders Association (NINCDSADRDA $)^{16}$ for probable Alzheimer's disease. Their median age was 70 (range 53-83) and they were all right handed. Table 1 gives their demographic and clinical data. All patients volunteered for an extensive study programme including medical interview, interview of relatives, clinical and neurological examination, blood tests, a detailed neuropsychological examination, cranial CT, cranial MRI, EEG, Doppler examination of neck arteries, and measurement of rCBF by SPECT with the ${ }^{133} \mathrm{Xe}$ inhalation technique, and high resolution SPECT with [ $\left.{ }^{99 \mathrm{~m}} \mathrm{Tc}\right]-d, l$-HMPAO.

For a diagnosis of probable Alzheimer's disease patients fulfilled the criteria for dementia from the Diagnostic and statistical manual of mental disorders (DSM-III-R). ${ }^{17}$ The severity of dementia was documented with the Mini-mental state (MMS) examination ${ }^{18}$ and the Blessed information-memory-concentration test. ${ }^{19}$ The functional state of the patient was graded using the Blessed dementia scale ${ }^{19}$ and the global deterioration scale. ${ }^{20}$ Depressive symptoms were rated with the Hamilton depression score. ${ }^{21}$ There were eight patients with mild (MMS $\geqslant 20$ ), 14 patients with moderate $(10 \leqslant M M S<20)$, and three patients with severe (MMS $<10$ ) dementia. All patients were still able to walk and talk, and none of them had severe psy-

Table 1 Clinical characteristics and CT of the brain in healthy control subjects and in patients with probable Alzheimer's disease

\begin{tabular}{|c|c|c|c|}
\hline & Control & $\begin{array}{l}\text { Alzheimer's } \\
\text { disease }\end{array}$ & Signif \\
\hline \multicolumn{4}{|l|}{ Clinical characteristics: } \\
\hline Number of patients & 25 & 25 & \\
\hline Females/males & $14 / 11$ & $16 / 9$ & \\
\hline Age $(y)$ & $70(53-83)$ & $70(53-83)$ & NS \\
\hline Age of onset $(y)$ & - & $64(48-79)$ & \\
\hline Duration of symptoms $(y)$ & - & $3(0 \cdot 5-7)$ & \\
\hline Mini-Mental state score $(0-30)^{18}$ & $30(27-30)$ & $14(3-27)$ & $\star \star$ \\
\hline Blessed I-M-C test $(0-37)^{19}$ & - & $18(0-34)$ & \\
\hline Blessed dementia scale $(0-28)^{19}$ & - & $10.5(0-19 \cdot 5)$ & \\
\hline Global deterioration scale $(1-7)^{20}$ & $1(1-2)$ & $5(3-6 d)$ & $\star \star$ \\
\hline Hamilton depression score $(0-54)^{21}$ & - & $0(0-10)$ & \\
\hline \multicolumn{4}{|l|}{ Social state: } \\
\hline Non-hospitalised healthy volunteer & 25 & 0 & \\
\hline Out-patients & 0 & 10 & \\
\hline Temporarily hospitalised & 0 & 10 & \\
\hline Permanently in hospital or nursing home & 0 & 5 & \\
\hline \multicolumn{4}{|l|}{ CT of the brain: } \\
\hline Focal abnormalities & None & None & \\
\hline Cortical atrophy score $(0-30)$ & $4(0-20)$ & $12(0-24)$ & $\star \star$ \\
\hline Frontal $(\mathrm{L}+\mathrm{R})$ & $1(0-6)$ & $2(0-6)$ & $\star$ \\
\hline Temporal $(\mathrm{L}+\mathrm{R})$ & $0(0-4)$ & $2(0-4)$ & $\star \star$ \\
\hline Insulae $(L+R)$ & $0(0-6)$ & $3(0-6)$ & $\star \star$ \\
\hline Parietal $(\mathbf{L}+\mathbf{R})$ & $2(0-6)$ & $2(0-6)$ & NS \\
\hline Occipital $(L+R)$ & $0(0-4)$ & $1(0-4)$ & NS \\
\hline Evans' ratio & $0.28(0.14-0.33)$ & $0.31(0.22-0.44)$ & $\star \star$ \\
\hline
\end{tabular}

${ }^{\star} \mathrm{p}<0.05 ;{ }^{\star \star} \mathrm{p}<0.01$ (Wilcoxon two-sample rank sum test). Values are medians (range); I-M-C = Information-Memory-Concentration; Signif = significance. chotic symptoms or behavioural abnormalities.

The presence of at least two cognitive deficits was documented by a detailed neuropsychological examination of cognitive functions including standard tests for orientation, memory, concentration and attention, abstraction and problem solving, language function, visual perception, visuoconstruction, and praxis. A reduction of the relevant cognitive score by more than 2 SDs from the control mean was required in memory and in at least one other cognitive area. A gradual onset and progression of symptoms, as well as duration of at least six months, was required for inclusion in the study. Fifteen of the patients had presenile onset (age of onset 48-65 years) and 10 had senile onset (age of onset 66-79 years) of symptoms.

Rigorous exclusion criteria were designed to select a sample of patients in which Alzheimer's disease was the only apparent dementia disorder and to exclude patients with any other disease that might be associated with dementia, reduced cognition, or altered rCBF: other neurological and psychiatric disorders (past or present) including any evidence of cerebrovascular disease or major cerebrovascular risk factors, focal pathology on CT, and abuse of alcohol or drugs led to exclusion of the patient. Medical disorders including impaired cardiopulmonary, renal, or hepatic function, hypothyroidism or hyperthyroidism, anaemia, vitamin B-12 deficiency, cancer, diabetes mellitus, and moderate to severe chronic arterial hypertension were also excluded. Clinical or paraclinical evidence for one of the conditions mentioned led to exclusion, even if it was not considered to be the relevant cause of dementia in that particular patient.

At the time of the SPECT study a diagnosis of probable Alzheimer's disease was obtained in 23 of the 25 patients, and a diagnosis of possible (or early probable) Alzheimer's disease was made in the remaining two patients (cases 21 and 34). Although the last two patients fulfilled the criteria for probable Alzheimer's disease in every other aspect, including deficits in two or more areas of cognition, memory impairment was not yet statistically significant. One of them (case 21) had moderate to severe impairment of concentration and abstraction and mild aphasia, the other (case 34) had pronounced aphasia and a mild limb apraxia. At their next visit to the clinic they had developed severe memory impairment and other cognitive deficits and they now fulfilled the criteria for probable Alzheimer's disease, still having no signs of cerebrovascular disease or other dementia disorders. A diagnosis of definite Alzheimer's disease was established by neuropathological examination at necropsy in one (case 19) of the patients with probable Alzheimer's disease.

The patients and their relatives gave informed consent to participation in the study, which was approved by the local ethics committee. 
CONTROL SUBJECTS

The results of SPECT and CT were compared with those of 25 control subjects with median age 70 (range 53-83). The control subjects were carefully screened healthy volunteers (not in hospital), presented in detail in a previous publication. ${ }^{22}$ They met the same exclusion criteria as the patients with Alzheimer's disease. Their neurological examination was normal, and cranial CT was without focal pathology (table 1).

\section{CT SCANS}

In 19 control subjects and in 19 patients with Alzheimer's disease a cranial CT scan of the brain was obtained with a Somatome DR II scanner (Siemens, Germany). In the remaining six control subjects and six patients a CT scan was obtained with an EMI 1000 scanner (Medical Hounslow, UK). Consecutive slices, thickness $8 \mathrm{~mm}$ (DR) or $10 \mathrm{~mm}$ (EMI) were obtained in parallel with the canthomeatal plane. The CT scans were randomly mixed with scans from patients with various other dementia disorders and healthy volunteers and evaluated by a radiologist who did not know the age and the diagnosis of the patient. All scans were carefully studied for any focal abnormalities, including infarcts and periventricular hypodensities, which led to the exclusion of the patient or control subject from the study. The degree of cortical atrophy was rated on a $0-3$ point scale $(0=$ none, $1=$ mild, $2=$ moderate, $3=$ severe) for five cortical regions (frontal, temporal, parietal, insulae, occipital) in each hemisphere. ${ }^{23}$ The scores were summed to calculate the total cortical atrophy score. Finally, the ratio of the width of the frontal horns of the lateral ventricles to the width of the inner skull-the Evans' ratio ${ }^{24}$ was measured.

\section{SPECT STUDIES}

${ }^{133} \mathrm{Xe}$ inhalation study

Before the [ $\left.{ }^{99 \mathrm{~m}} \mathrm{Tc}\right]-d, l$-HMPAO study, a cerebral blood flow assessment was made with the ${ }^{133} \mathrm{Xe}$ inhalation technique using a Tomomatic 64 (Medimatic, Hellerup, Denmark), a rapidly rotating and highly sensitive three slice instrument for brain SPECT described in detail elsewhere. ${ }^{25}$ This study was performed to obtain absolute measures for global CBF and for mean blood flow in the cerebellum, which was used as the region of reference for the data obtained in the subsequent $\left[{ }^{99 \mathrm{~m}} \mathrm{Tc}\right]-$ d,l-HMPAO study. ${ }^{22}$ During both studies the patients were resting with eyes closed and ears unplugged in quiet surroundings. In the ${ }^{133} \mathrm{Xe}$ inhalation study, ${ }^{133} \mathrm{Xe}$ was inhaled during 1.5 minutes from a 4 litre bag filled with atmospheric air and oxygen with a ${ }^{133} \mathrm{Xe}$ concentration of $740 \mathrm{MBq} / 1$, by means of a closed system with a $\mathrm{CO}_{2}$ absorber. Two studies were performed to obtain a total of six image slices in parallel with the canthomeatal plane. At the end of each study the end expiratory $\mathrm{CO}_{2}$ fraction was measured with a capnograph (CDA-1 $\mathrm{CO}_{2}$ analyser, Novo Diagnostic Systems, Denmark). Methods for calculation of blood flow and regional data analysis are described in detail elsewhere. ${ }^{22} 26$

\section{$\left.{ }^{99 m} T c\right]-d, l-H M P A O$ study}

A saline bolus containing $1 \cdot 1 \mathrm{GBq}\left[{ }^{99 \mathrm{~m}} \mathrm{Tc}\right]-d, l-$ HMPAO (Exametazime, Ceretec, Amersham, London, UK) was injected intravenously 10-20 minutes before data acquisition. Again, the activity in the brain was measured with the Tomomatic 64 instrument. With this technique the slice thickness and the resolution in the plane is $10 \mathrm{~mm}$ full width at half maximum. All scans were obtained in parallel with the canthomeatal plane. The acquisition time was 25 minutes, yielding at least $3 \times 10^{6}$ counts per slice. Data acquisition was performed at three different levels to obtain nine contiguous image slices covering the whole brain. ${ }^{22}$ After reconstruction, the data were normalised to the cerebellum and corrected to adjust for incomplete retention of the tracer by the algorithm described by Lassen et $a l^{2}$ with a conversion:clearance ratio of $1 \cdot 5$. The cerebellar hemisphere with the highest count rate was used as the reference region, and its count rate was determined by a lower $60 \%$ fractile threshold. ${ }^{22}$

The procedure for regional analysis of [ $\left.{ }^{99 \mathrm{~m}} \mathrm{Tc}\right]-d, l$-HMPAO data was described in detail in a previous publication. ${ }^{22}$ Briefly, regions of interest were drawn on each slice with reference to predefined standardised templates with bilateral and symmetrical regions of interest. The design of these templates was performed with reference to an anatomical atlas of the brain ${ }^{27}$ and based on anatomical structures that are easily recognisable on a typical SPECT image. ${ }^{22}$ Figure 1 shows the presentation of canthomeatal planes and regions of interest in relation to the lateral brain surface. For each region of interest the mean pixel value $\left(\mathrm{F}_{\mathrm{i}, \mathrm{s}}\right)$ and the area of the region were determined in each slice in which the region of interest appeared, ${ }^{22}$ and a weighted mean flow value was calculated for the entire left $\left(F_{i(L)}\right)$ and right $\left(F_{i(R)}\right)$ regions of interest. The side-to-side asymmetry index (SAI) was defined as:

$$
\operatorname{SAI}_{\mathrm{i}}(\%)=100 \times \frac{\mathrm{F}_{\mathrm{i}(\mathrm{R})}-\mathrm{F}_{\mathrm{i}(\mathrm{L})}}{\mathrm{F}_{\mathrm{i}(\max )}}
$$

where $F_{i}(\max )$ is the blood flow in the higher of the two regions of interest. For the intergroup comparisons of side-to-side asymmetry, the numerical values ( $|S A I|)$ were used. The anterior:posterior ratios were calculated as the ratio of the mean $\mathrm{rCBF}$ in the frontal cortex to the mean $\mathrm{rCBF}$ in the temporal cortex $\left(\mathrm{F}_{(\mathrm{F})} / \mathrm{F}_{(\mathrm{T})}\right)$ or the parietal cortex $\left(\mathrm{F}_{(\mathrm{F})} / \mathrm{F}_{(\mathrm{P})}\right)$.

\section{Radiation exposure}

The estimated total radiation exposure in the SPECT study with two ${ }^{133} \mathrm{Xe}$ inhalation studies and one intravenous $1 \cdot 1 \mathrm{GBq}\left[{ }^{99 \mathrm{~m}} \mathrm{Tc}\right] d, l-$ HMPAO dose was $16 \mathrm{mSv}^{22}$

\section{DATA ANALYSIS AND STATISTICS}

The statistical analysis of the [ $\left.{ }^{99 \mathrm{~m}} \mathrm{Tc}\right]-d, l-$ HMPAO data from the many regions of interest began with a two factor analysis of 
Figure 1 Schematic drawing of a lateral view of the left hemisphere with localisation of the 10 anatomical standard slices parallel to the canthomeatal plane $(A)$ and cortical regions of interest (B). $V$ indicates distance from the vertex of the atlas brain. Complete list of regions of interest: $F=$ frontal cortex $F 1=$ upper frontal cortex; $F 2$ = precentral gyrus; F3 = superior frontal gyrus and cingulate gyrus; F4 = middle frontal gyrus $F 5=$ inferior frontal gyrus, F6 = orbitofrontal gyrus; $T=$ temporal cortex; $T 1=$ superior temporal gyrus and insula cortex; $T 2=$ inferior and middle temporal gyrus;

$T 3=$ temporal poles $P=$ parietal cortex $P 1=$ upper parietal cortex P2 = postcentral gyrus; P3 = supramarginal and angular gyrus; $O C=$ occipital cortex . Reproduced with permission from Waldemar et al. ${ }^{22}$

\section{A}

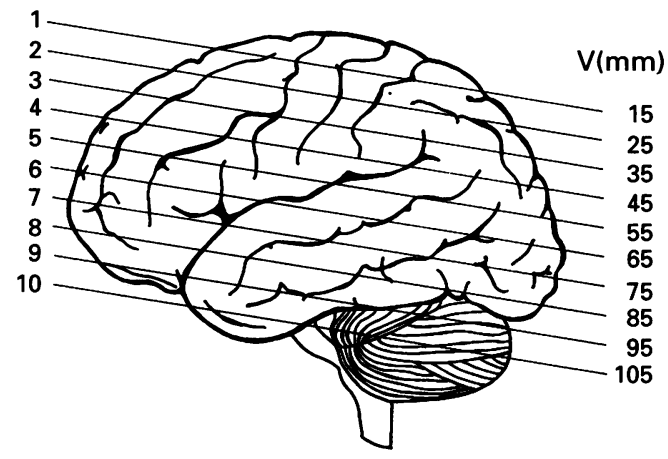

B

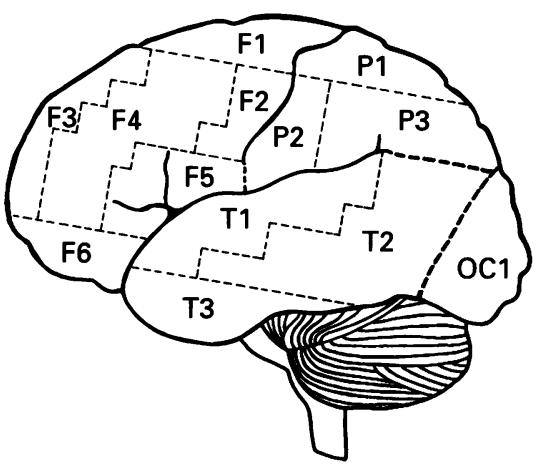

variance. This analysis would assess whether any significant differences in $F(\%)$ was attributable to region of interest, to group (Alzheimer's disease $v$ control group), or to interaction between these two explanatory factors. A significant effect of group, or region of interest, would indicate that the differences in the means between the two groups, or between the regions of interest, respectively, were greater than expected from the inherent variance of the data. A significant interaction of factors would indicate that there was a disproportionate difference between the groups of $F(\%)$ in at least one region of interest. The factorial analysis of variance was also applied to the regional data for side-to-side asymmetry.

The Wilcoxon two sample rank sum test (with Bonferroni correction of $p$ values to adjust for the effect of multiple comparisons) was applied post hoc to compare the mean values of each region of interest in the two groups. The Wilcoxon two sample rank sum test was also used to compare other variables. The Spearman rank correlation coefficients were used to examine the relation between rCBF and clinical characteristics. The level of statistical significance was set at $\mathbf{p}=0.05$.

\section{Individual $r C B F$ patterns}

Firstly, 14 theoretical and simple rCBF patterns (one normal and 13 abnormal) were defined (fig 2). Reflecting gross anatomy, these patterns comprised only four regions: a left and a right frontal region and a left and a right posterior region, in which $\mathrm{rCBF}$ was characterised as either normal or reduced. The frontal region comprised all regions of interest in the frontal cortex. The posterior region comprised all regions of interest in the temporal cortex (and the hippocampus), the parietal cortex, and the occipital cortex (fig 1B). Twelve of the 14 possible patterns are shown in fig 2 . The remaining two patterns showed normal rCBF and reduced rCBF, respectively, in all four possible regions.

Secondly, the rCBF data for each patient were analysed with reference to the normal ranges for internal $\mathrm{rCBF}$ ratios according to the following criteria: in each of the four regions $\mathrm{rCBF}$ was described as reduced if the relevant side-to-side asymmetry or anterior:posterior ratio was significantly abnormal, or if the mean $\mathrm{rCBF}$ value $(\mathrm{F}(\%)$ ) was severely reduced. The third criterion was included in order not to overlook regions with a severe focal reduction of blood flow, despite normal internal ratios. For instance, the left frontal region was characterised as having reduced rCBF if (1) the left frontotemporal or frontoparietal ratio was significantly reduced $\left(\left(F_{(\mathrm{F})} / \mathbf{F}_{(\mathrm{T})}\right)\right.$ or $\left(\mathbf{F}_{(\mathrm{F})} / \mathbf{F}_{(\mathrm{P})}\right)$ reduced by more than 2 SDs from control mean); (2) $F(\%)$ was reduced significantly compared with its contralateral counterpart in at least one of the cortical regions of interest in the left frontal cortex (side-to-side asymmetry increased by more than 2 SDs from control mean); or (3) $F(\%)$ was reduced by more than 3 SDs from the control mean in at least one of the cortical regions of interest in the left frontal cortex. Equivalent criteria were applied to the right frontal region. Likewise, the left posterior region was characterised as having reduced rCBF if (1) the left frontotemporal or frontoparietal ratio was significantly increased; (2) $F(\%)$ was reduced significantly compared

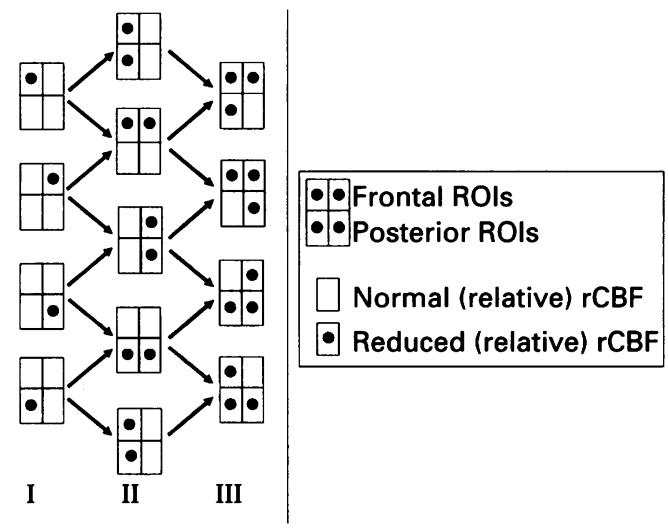

Figure 2 Schematic illustration of the predefined types of abnormal rCBF patterns. The two top regions in each pattern show the frontal region comprising all regions of interest in the frontal cortex. The two lower regions illustrate the posterior regions of the brain comprising the temporal, parietal, and occipital cortex and the hippocampus. The left hemisphere is to the left. A filled circle indicates a significant relative reduction of $r C B F$. The pattern showing reduced $r C B F$ in all four possible regions is not shown. The arrows illustrate the theoretical hypothesis concerning the relation of $r C B F$ patterns with the duration of disease in probable Alzheimer's disease: The number of abnormal regions in the rCBF patterns correlated significantly with the duration of disease. In the patterns with three hypoperfused regions (type III), the CCBF reduction was significantly more pronounced in the intermediate of the three affected regions. Therefore, the three types of patterns showing reduced rCBF in 1 (type I), 2 (type II), or 3 (type III) of the four possible regions of the brain could reflect different stages (early, intermediate, and advanced, respectively) of the disease. 
with its contralateral counterpart in at least one of the cortical regions of interest in the left posterior region; or (3) $F(\%)$ was reduced by more than 3 SDs from the control mean in at least one of the cortical regions of interest in the left posterior region. Equivalent criteria were applied to the right posterior region. An rCBF pattern was characterised as abnormal if at least one of its four regions had reduced rCBF according to these criteria.

The Spearman rank correlation coefficients were used to examine the relation between the number of affected regions in the rCBF patterns and clinical characteristics. The Wilcoxon matched pairs test was used to compare the reduction of $\mathrm{rCBF}$ (calculated as the deviation in number of SDs from control mean) in adjacent regions of the rCBF pattern. The Wilcoxon two sample rank sum test was used to compare the duration of disease, disease onset, and MMS score in patients with and without frontal changes.

\section{Results}

\section{CT STUDIES}

The median cortical atrophy score was 4 $(0-20)$ and $12(0-24)$ in the control and the Alzheimer's disease group, respectively ( $p<$ $0.01)$. Only in the frontal lobes $(p<0.05)$ and in the temporal regions and insulae $(p<0.01)$ were the regional atrophy scores significantly higher in the Alzheimer's disease group (table 1). There was no significant side-to-side asymmetry of the cortical atrophy scores and no severe unilateral or local atrophy in any patient. The median Evans' ratio was 0.28 $(0.14-0.33)$ and $0.31(0.22-0.44)$ in the control and the Alzheimer's disease groups, respectively $(p<0.01)$.
GROUP COMPARISONS OF GLOBAL AND ICBF ${ }^{133} \mathrm{Xe}$ inhalation data

In the group of patients with Alzheimer's disease as a whole there was a significant reduction of global $\mathrm{CBF}$ and of $\mathrm{rCBF}$ in all cortical regions of interest. Global CBF was $56.6(9.3) \mathrm{ml} / 100 \mathrm{~g} / \mathrm{min}$ and $48.4(10.2) \mathrm{ml} /$ $100 \mathrm{~g} / \mathrm{min}$ in the control and Alzheimer's disease groups, respectively $(p<0.01)$. There was no significant difference in rCBF in the cerebellum $(64.5(10.7)$ and $62.7(10.1) \mathrm{ml} /$ $100 \mathrm{~g} / \mathrm{min}$ in the control and Alzheimer's disease groups, respectively) or in the end expiratory $\mathrm{CO}_{2}$ fraction between the two groups.

\section{$\left.{ }^{99 m} T c\right]-d, l-H M P A O$ data}

Global CBF, as measured with the [ ${ }^{99 \mathrm{~m}} \mathrm{Tc}$ ]$d, l$-HMPAO method and normalised to the cerebellum (table 2), was $84 \cdot 8(8.4) \%$ in the control group and $74.2(8.8) \%$ in the Alzheimer's disease group $(p<0.01)$. The two factor analysis of variance applied to the rCBF $(F(\%))$ data showed a significant overall effect of group $\left(F_{\text {group }}=93.3 ; p<0.001\right)$ as well as of region of interest $\left(\mathrm{ROI} ; \mathrm{F}_{\mathrm{ROI}}=44.7\right.$; $\mathrm{p}<0.001$ ), but there was no significant interaction between region of interest and group $\left(F_{\text {interaction }}=0.6 ; p>0.10\right)$. Thus the factorial analysis of variance gave significant evidence for a diffuse reduction of $\mathrm{CBF}$, but not for a consistent focal or multifocal reduction of rCBF in the group of patients as a whole. As shown in table 2 , however, conventional post hoc comparisons of the rCBF data in the two groups showed a significant hypoperfusion in the superior, middle, and orbitofrontal cortex (regions F3, F4, and F6 in fig. 1B), in all temporal cortex regions of interest and the hippocampus, and in most of the parietal cortex (P2 and P3). The precentral and inferior

Table 2 High resolution SPECT with P9m Tc]-d, l-HMPAO in Alzheimer's disease: regional cerebral blood flow $(F(\%))$, linearised and normalised to the cerebellum, and side to side asymmetry index $(|S A I|)$, in control subjects and in patients with probable Alzheimer's disease

\begin{tabular}{|c|c|c|c|c|c|c|c|}
\hline \multirow[b]{2}{*}{$\begin{array}{l}\text { Regions of } \\
\text { interest }\end{array}$} & \multirow[b]{2}{*}{ Slices } & \multicolumn{3}{|c|}{$F(\%)($ mean $(S D)$} & \multicolumn{3}{|c|}{$|S A I|$ (mean) } \\
\hline & & Control & $\begin{array}{l}\text { Alzheimer's } \\
\text { disease }\end{array}$ & Signif & Control & $\begin{array}{l}\text { Alzheimer's } \\
\text { disease }\end{array}$ & Signif \\
\hline Hemispheres & $2-8$ & $84 \cdot 8(8 \cdot 4)$ & $74 \cdot 2(8 \cdot 8)$ & $\star \star$ & $2 \cdot 3$ & $6 \cdot 0$ & $\star \star$ \\
\hline Frontal cortex $(F)$ & 1 & $82 \cdot 8(7 \cdot 1)$ & $73 \cdot 0(7 \cdot 3)$ & $\star \star \star \star$ & $2 \cdot 2$ & $5 \cdot 7$ & $\star \star$ \\
\hline Upper frontal (F1) & $2-4$ & $81.5(8.0)$ & $75 \cdot 2(9 \cdot 4)$ & NS & $5 \cdot 2$ & $5 \cdot 3$ & NS \\
\hline Precentral gyrus (F2) & $2-7$ & $84 \cdot 2(9 \cdot 4)$ & $77 \cdot 2(8 \cdot 1)$ & NS & $5 \cdot 7$ & $6 \cdot 7$ & NS \\
\hline \multicolumn{8}{|l|}{ Superior frontal } \\
\hline and cingulate gyrus (F3) & $2-7$ & $81 \cdot 4(8 \cdot 5)$ & $71 \cdot 8(9 \cdot 0)$ & $\star \star$ & $2 \cdot 1$ & $4 \cdot 9$ & ^ \\
\hline Middle frontal gyrus (F4) & $5-7$ & $82 \cdot 7(8 \cdot 0)$ & $71 \cdot 4(10 \cdot 0)$ & $\star \star \star$ & $3 \cdot 5$ & $7 \cdot 5$ & $\star$ \\
\hline Inferior frontal gyrus (F5) & $5-7$ & $86 \cdot 6(10 \cdot 8)$ & $77 \cdot 1(10 \cdot 0)$ & NS & $4 \cdot 1$ & $7 \cdot 3$ & NS \\
\hline Orbitofrontal (F6) & 8-9 & $83 \cdot 3(7 \cdot 8)$ & $70 \cdot 6(7 \cdot 7)$ & $\star \star \star$ & $3 \cdot 3$ & $6 \cdot 4$ & NS \\
\hline Temporal cortex $(\mathrm{T})$ & & $88 \cdot 6(7 \cdot 4)$ & $74 \cdot 7(10 \cdot 3)$ & $\star \star \star$ & $4 \cdot 6$ & $9 \cdot 0$ & NS \\
\hline \multicolumn{8}{|l|}{ Superior temporal gyrus } \\
\hline and insula cortex (T1) & $5-8$ & $91 \cdot 4(10 \cdot 3)$ & $78 \cdot 0(11 \cdot 2)$ & $\star \star$ & $6 \cdot 1$ & $9 \cdot 9$ & NS \\
\hline \multicolumn{8}{|l|}{ Inferior and middle } \\
\hline Temporal poles (T3) & 9-10 & $\begin{array}{l}89.3(10.3) \\
78.9(6.9)\end{array}$ & $\begin{array}{l}75 \cdot 3(11 \cdot 9) \\
65 \cdot 2(8 \cdot 7)\end{array}$ & 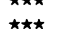 & $\begin{array}{l}4 \cdot 3 \\
5.4\end{array}$ & $\begin{array}{r}9 \cdot 2 \\
11 \cdot 1\end{array}$ & NS \\
\hline Parietal cortex $(\mathbf{P})$ & & $88 \cdot 5(9 \cdot 7)$ & $76.9(11 \cdot 1)$ & $\star \star$ & $3 \cdot 1$ & $6 \cdot 1$ & NS \\
\hline Upper parietal (P1) & 1 & $85 \cdot 2(9 \cdot 2)$ & $79 \cdot 0(13 \cdot 6)$ & NS & $4 \cdot 4$ & $4 \cdot 5$ & NS \\
\hline Postcentral gyrus (P2) & $2-4$ & $86 \cdot 9(10 \cdot 7)$ & $75 \cdot 9(9 \cdot 7)$ & $\star$ & $5 \cdot 9$ & $7 \cdot 7$ & NS \\
\hline \multicolumn{8}{|l|}{ Supramarginal } \\
\hline $\begin{array}{l}\text { and angular gyrus (P3) } \\
\text { Occipital cortex (OC) }\end{array}$ & $\begin{array}{l}2-3 \\
4-8\end{array}$ & $\begin{array}{r}92 \cdot 5(11 \cdot 4) \\
102.8(12.1)\end{array}$ & $77 \cdot 0(13 \cdot 5)$ & NA & $3 \cdot 3$ & $7 \cdot 4$ & NS \\
\hline $\begin{array}{l}\text { Occipital cortex (OC) } \\
\text { Hippocampus }(\mathrm{HC})\end{array}$ & $\begin{array}{l}4-0 \\
8-9\end{array}$ & $83 \cdot 2(6 \cdot 9)$ & $\begin{array}{l}94 \cdot 4(12 \cdot 3) \\
71 \cdot 5(9 \cdot 5)\end{array}$ & $\lim _{\star \star \star}$ & $\begin{array}{l}2 \cdot 9 \\
4 \cdot 4\end{array}$ & $\begin{array}{r}4 \cdot 0 \\
10 \cdot 1\end{array}$ & $\operatorname{lin}_{\star \star}$ \\
\hline Thalamus & $5-6$ & $98 \cdot 3(27 \cdot 9)$ & $82 \cdot 5(18 \cdot 6)$ & NS & 8.5 & $9 \cdot 7$ & NS \\
\hline Lenticular nucleus & $6-7$ & $103 \cdot 3(14 \cdot 2)$ & $90 \cdot 1(18 \cdot 5)$ & NS & $5 \cdot 4$ & $9 \cdot 1$ & NS \\
\hline Caudate nucleus & $6-7$ & $91 \cdot 8(11 \cdot 1)$ & $78 \cdot 0(15 \cdot 3)$ & NS & $6 \cdot 5$ & $14 \cdot 4$ & NS \\
\hline Centrum semiovale & $3-4$ & $61 \cdot 5(6 \cdot 6)$ & $53.9(11.9)$ & NS & $5 \cdot 8$ & $9 \cdot 6$ & NS \\
\hline
\end{tabular}

${ }^{\star} \mathrm{p}<0.05 ;{ }^{\star \star} \mathrm{p}<0.01 ;{ }^{\star \star \star} \mathrm{p}<0.001$ (Wilcoxon two sample rank sum test with Bonferroni corrected $\mathrm{p}$ values). Slices $=$ anatomical reference slices included in the region of interest, see fig 1 . F $(\%)=$ regional cerebral blood flow relative to cerebellar blood flow, $|\mathrm{SAI}|=$ numerical side to side asymmetry index; Signif = significance. 
Table 3 High resolution SPECT with [99m Tc]-d,l-HMPAO in Alzheimer's disease: cortical regions with reduced rCBF according to each of two criteria in individual patients

\begin{tabular}{|c|c|c|c|c|}
\hline \multirow{2}{*}{$\begin{array}{l}\text { Patient/case } \\
\text { No }\end{array}$} & \multicolumn{2}{|c|}{ Abnormal anterior: posterior ratio } & \multicolumn{2}{|c|}{ Abnormal side-to-side asymmetry index } \\
\hline & Left & Right & Left & Right \\
\hline $01 / 02$ & T,P & T,P & - & F,F3,T,T2,P3 \\
\hline $02 / 09$ & - & $\mathrm{F}$ & - & - \\
\hline $03 / 15$ & $\mathrm{~T}$ & - & $\mathrm{T}, \mathrm{T} 2, \mathrm{P}, \mathrm{P} 1, \mathrm{P} 3$ & - \\
\hline $04 / 17$ & $\mathbf{F}$ & $\mathrm{F}$ & $\mathrm{F}, \mathrm{F} 3-4, \mathrm{~F} 6, \mathrm{~T} 1$ & - \\
\hline $05 / 19$ & $\mathrm{~T}$ & $\mathrm{~T}, \mathrm{P}$ & - & $\mathrm{F}, \mathrm{F} 2, \mathrm{~F} 4, \mathrm{~T}, \mathrm{~T} 2, \mathrm{P}, \mathrm{P} 2, \mathrm{OC}$ \\
\hline $06 / 21$ & - & $\mathbf{F}$ & - & $\mathrm{F}, \mathrm{T} 3, \mathrm{HC}$ \\
\hline $07 / 22$ & $\mathrm{~T}$ & $T$ & $F, F 3-4$ & - \\
\hline $08 / 23$ & $\mathrm{~T}, \mathrm{P}$ & $\mathrm{T}, \mathrm{P}$ & HC,P2,OC & - \\
\hline $09 / 25$ & - & - & $\mathrm{HC}^{\star}$ & $\mathrm{F} 1, \mathrm{~F} 3, \mathrm{HC}$ \\
\hline $10 / 26$ & $\mathbf{F}$ & $\mathbf{F}$ & P3 & - \\
\hline $11 / 28$ & $\mathrm{~T}$ & - & F3,F6,T,T1-3,HC & T3* \\
\hline $12 / 32$ & $\mathbf{T}$ & - & $\mathrm{F}, \mathrm{F} 5, \mathrm{~T}, \mathrm{~T} 2-3, \mathrm{HC}, \mathrm{P}, \mathrm{P} 3, \mathrm{OC}$ & - \\
\hline $13 / 33$ & $\mathbf{T}$ & $\mathrm{T}$ & - & $\mathrm{F}, \mathrm{F} 3, \mathrm{~F} 6, \mathrm{~T} 1, \mathrm{HC}$ \\
\hline $14 / 34$ & - & - & F5 & \\
\hline $15 / 35$ & $\mathbf{T}, \mathbf{P}$ & $\mathrm{T}, \mathrm{P}$ & - & $\mathrm{F}, \mathrm{F} 2-5, \mathrm{~T}, \mathrm{~T} 1-3, \mathrm{HC}, \mathrm{P}, \mathrm{P} 1, \mathrm{P} 3$ \\
\hline $16 / 37$ & - & $\bar{\pi}$ & F,F3-6,T,T1-3,HC,P,P3 & F1 \\
\hline $17 / 41$ & $\mathrm{~T}$ & $\mathbf{T}$ & $\mathrm{F}, \mathrm{F} 4-6, \mathrm{~T}, \mathrm{~T} 1-3, \mathrm{HC}, \mathbf{P}, \mathrm{P} 2-3$ & - \\
\hline $18 / 42$ & $\mathbf{F}$ & $\mathrm{F}$ & HC & - \\
\hline $19 / 43$ & - & $\mathbf{T}, \mathbf{P}$ & - & $\mathrm{T}, \mathrm{T} 1, \mathrm{~T} 3, \mathrm{HC}$ \\
\hline $20 / 44$ & - & - & - & OC \\
\hline $21 / 45$ & - & - & F,F3-6,HC & - \\
\hline $22 / 47$ & - & $\mathbf{P}$ & - & - \\
\hline $23 / 51$ & $\mathrm{~T}$ & - & T2,P,P3 & - \\
\hline $24 / 52$ & $\mathrm{~T}, \mathrm{P}$ & T,P & $-3=$ & F6,HC,P,P3,OC \\
\hline $25 / 53$ & $\mathrm{~T}$ & $\mathrm{~T}, \mathrm{P}$ & - & $\mathrm{F}, \mathrm{F} 2, \mathrm{~F} 6, \mathrm{~T} 3, \mathrm{P} 3$ \\
\hline
\end{tabular}

For a definition of regions see fig 1B. This list of regions with reduced rCBF was used to select the appropriate rCBF pattern in each patient (shown in fig 3). ${ }^{\star}$ In these subregions rCBF was reduced by more than 3 SDs from the control mean, but was not reduced according to either of the two asymmetry criteria. All other regions with rCBF reduction exceeding 3 SDs (not listed) also fulfilled at least one of the two asymmetry criteria for reduced rCBF.

frontal cortex (F2 and F5), the upper frontoparietal regions (F1 and $P 1)$, the occipital cortex (OC), and the subcortical regions were relatively spared.

Likewise, the two-factor analysis of variance applied to the regional side-to-side asymmetry data (table 2) showed a significant overall effect of group $\left(F_{\text {group }}=57 \cdot 1 ; p<0.01\right)$ as well as of region of interest $\left(\mathrm{F}_{\mathrm{ROI}}=8 \cdot 6, \mathrm{p}<\right.$ 0.01 ), but the interaction between group and region of interest only approached statistical significance $\left(F_{\text {interaction }}=1.78 ; 0.05<p<0.10\right)$. Thus the factorial analysis of variance gave significant evidence for a diffuse increase of side-to-side asymmetry of rCBF, but there was no significant evidence that any of the

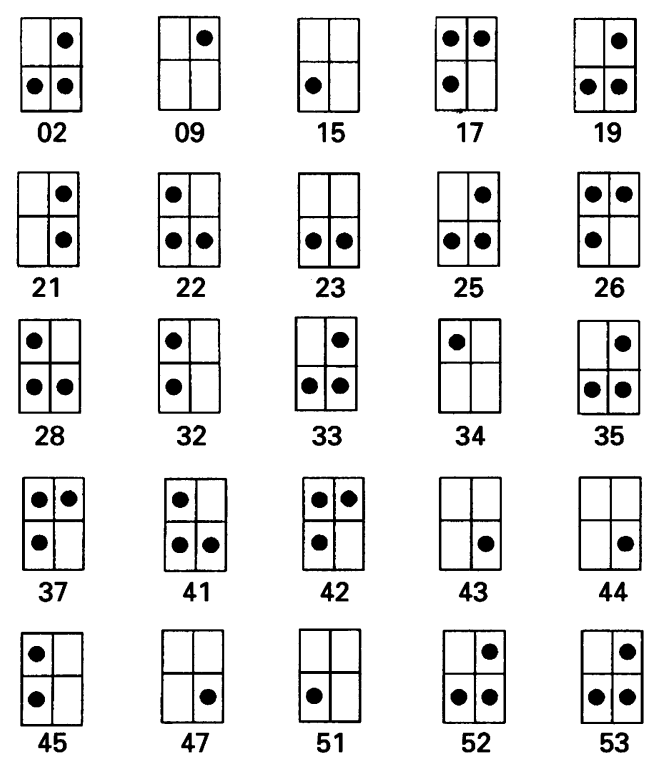

Figure 3 Abnormal rCBF patterns in the 25 patients with probable Alzheimer's disease. The case numbers are shown below each pattern. For a definition of symbols, see fig 2 . A pronounced heterogeneity of rCBF patterns is seen. regions of interest were more asymmetrical than others in the group of patients with Alzheimer's disease as a whole. Conventional post hoc comparisons of the regional side-toside asymmetry data (table 2) showed significantly increased side-to-side asymmetry of $\mathrm{rCBF}$, however, in the superior and middle frontal cortex (F3 and F4) and in the hippocampus.

The fronto:temporal ratio of $\mathrm{rCBF}$ was $0.94(0.03)$ in the control group and 0.99 $(0 \cdot 10)$ in the Alzheimer's disease group ( $\mathrm{p}<$ 0.05 ). There was no significant difference in the fronto:parietal ratio of $\mathrm{rCBF}$ in the two groups.

INDIVIDUAL PATTERNS OF ICBF MEASURED WITH [ $\left.{ }^{99 \mathrm{~m}} \mathrm{Tc}\right]-d, l$-HMPAO

All patients, (but none of the control subjects) had an abnormal rCBF pattern. Table 3 shows how each patient fulfilled the criteria for an abnormal pattern and fig 3 illustrates the resulting abnormal rCBF patterns. A pronounced topographical heterogeneity of rCBF patterns, as regards the number of affected regions, laterality, and anterior-posterior asymmetry, was found (fig 3). Eleven of the 13 theoretically possible rCBF patterns were seen in the 25 patients. There were seven, four, and 14 patients with $\mathrm{rCBF}$ reduction in one, two, or three of the four possible regions in the rCBF patterns, respectively (types I, II, and III patterns in fig 2).

Eleven (44\%) of the 25 patients had bilateral posterior hypoperfusion, which in 10 of them was associated with unilateral frontal hypoperfusion. Twelve (48\%) patients had unilateral posterior hypoperfusion, which in seven of them was associated with either unilateral or bilateral frontal hypoperfusion. The remaining two patients had normal posterior rCBF. In total 19 patients (76\%) had reduced frontal rCBF and six patients had normal frontal rCBF (fig 3). 

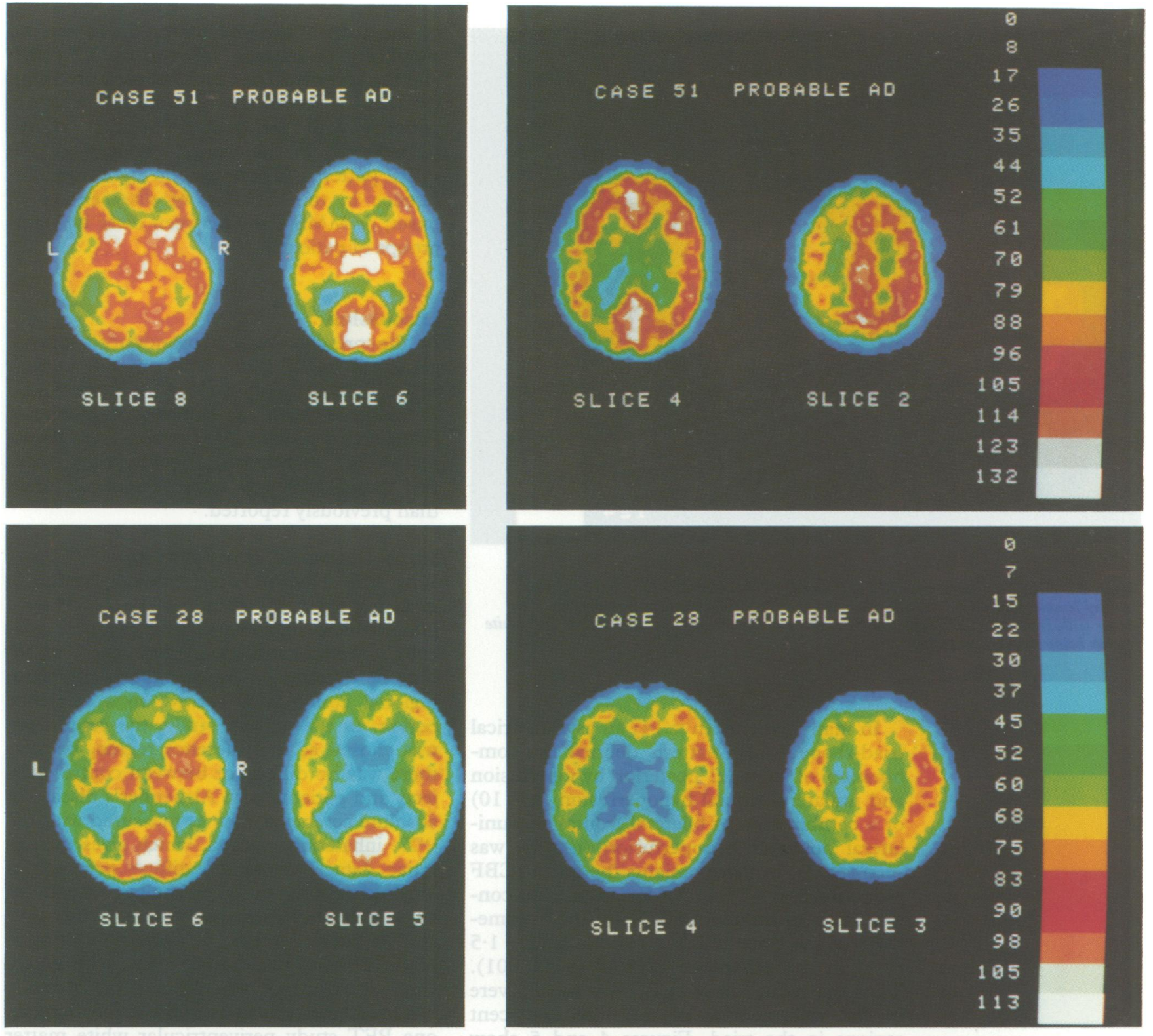

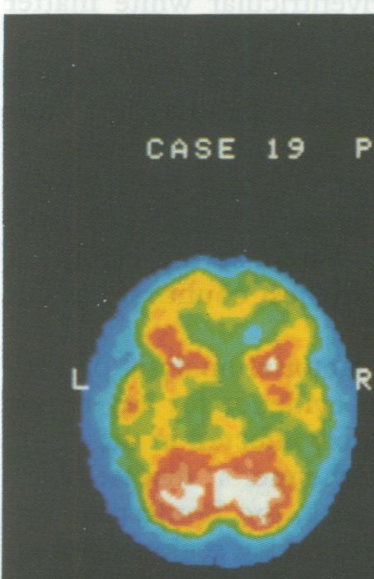

SLICE 8

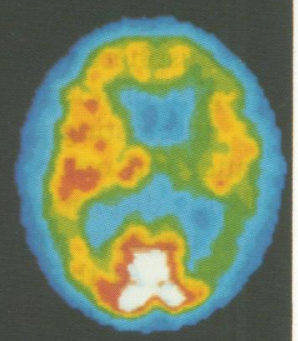

SLICE 6

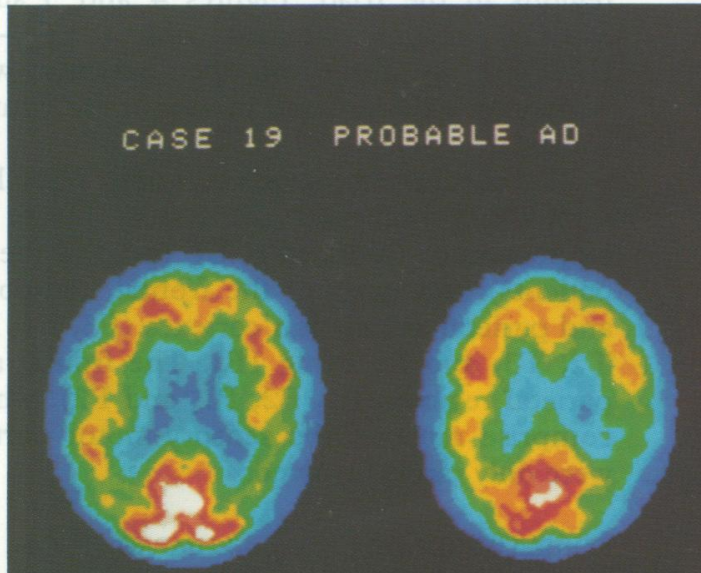

SLICE 4
0

15

22

30

37

45

52

60

68

75

83

90

SLICE 3

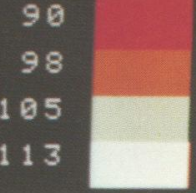

Figure 4 rCBF measured with SPECT and ${ }^{\mathrm{Pm}}$ Tcl-d,l-HMPAO in three patients with a clinical diagnosis of probable Alzheimer's disease. Four slices are shown for each patient. The location of slice numbers is shown in fig 1 , and in all slices the left hemisphere is to the left. The colour scale indicates $r C B F$, given in \% relative to the cerebellum, with the red and white colours being the highest values. Top: 64-year-old right handed female patient (case 51) with probable Alzheimer's disease. This patient presented with mild dementia (MMS score 21), a pronounced anomia, a slight but significant impairment of memory and visuoperception, and mild construction apraxia. A significant reduction of $r C B F$ was seen in the left temporoparietal cortex only. The side to side asymmetry seen in the frontal cortex by visual inspection of the image was not significantly abnormal. Middle: 68-year-old right handed male patient (case 28) with probable (and familial) Alzheimer's disease. This patient had moderate dementia (MMS score 12) with severe memory impairment, aphasia, and visual agnosia. A moderate impairment of concentration and abstraction was also noted, whereas constructional skills were normal. A significant reduction of $r C B F$ was seen in the left frontal and left temporal cortex, including the hippocampus, and in the right temporal pole (not shown). Bottom: 72-year-old right handed female patient (case 19) with probable (and familial) Alzheimer's disease. In this patient the diagnosis was later confirmed at necropsy, four years after the SPECT study. The patient had moderate dementia (MMS score 15) with severe construction apraxia and memory impairment. A moderate aphasia and visual agnosia was also noted, whereas concentration and abstraction abilities were not impaired. A significant reduction of $r C B F$ was seen in the right frontal cortex, the left and right temporal cortex, and in the right parietal and occipital cortex. 


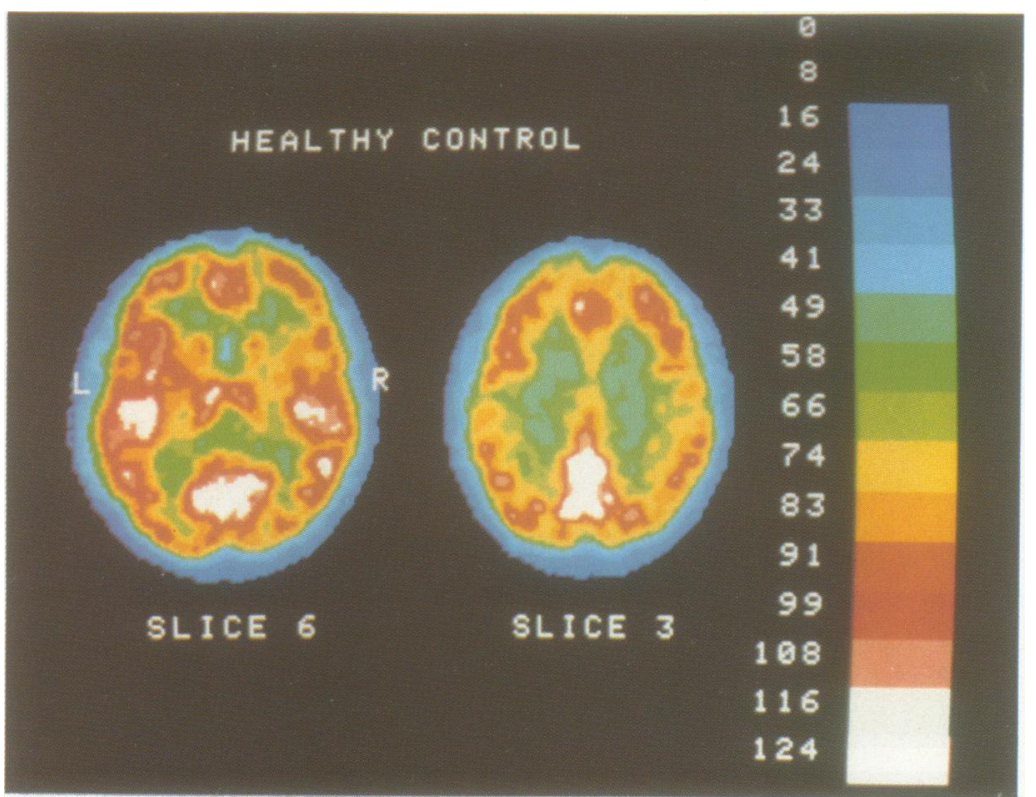

Figure 5 CCBF measured with SPECT and $\left.{ }^{99 m} T c\right]-d, l-H M P A O$ in a 56-year-old healthy female volunteer. Two slices are shown. The left hemisphere is to the left. The colour scale indicates $r C B F$, given in $\%$ relative to the cerebellum, with the red and white colours being the highest values. or the cortical atrophy score. There was no significant correlation between frontal rCBF and the severity of dementia as measured with the MMS score. There were 19 and six patients with reduced or normal rCBF, respectively, in the frontal region(s) of the rCBF patterns. There was no significant difference in the duration of disease, age of onset, or MMS score between these two subgroups of patients.

\section{Discussion}

In the present study a pronounced heterogeneity of rCBF patterns, as measured with SPECT and [ $\left.{ }^{99 \mathrm{~m}} \mathrm{Tc}\right]-d, l$-HMPAO, was found in patients with a clinical diagnosis of Alzheimer's disease. All patients had abnormal rCBF patterns with focal hypoperfusion, and frontal changes were seen more often than previously reported.

\section{METHODOLOGICAL CONSIDERATIONS}

With the HMPAO technique quantitative measures for rCBF require arterial blood sampling, which is associated with practical difficulties. Semiquantitative estimates of rCBF may be determined by calculating the mean regional count rates relative to a reference region. In the present study, the cerebellum was chosen as the reference region, because there was no difference between control subjects and patients with Alzheimer's disease in absolute cerebellar flow as measured with the ${ }^{133} \mathrm{Xe}$ inhalation method, which gives quantitative data. Despite the diffuse presence of amyloid deposits in the cerebellum of patients with Alzheimer's disease, ${ }^{28}$ neuropathological studies have found no or only slight atrophy of the cerebellum, even in cases with severe cerebral atrophy. ${ }^{29}$ No other SPECT study has found abnormalities in the cerebellum. In one PET study periventricular white matter lesions on CT was associated with raised cerebellar glucose metabolism, ${ }^{30}$ and in another PET study crossed cerebellar diaschisis was noted. ${ }^{31}$ Our patients had no periventricular white matter lesions on CT, and crossed cerebellar diaschisis, if present, could not have affected our data as we chose the cerebellar hemisphere with the highest count rate as our region of reference.

Interestingly, the factorial analysis of variance did not provide evidence for any region being disproportionately affected in the group of patients with Alzheimer's disease as a whole. At the same time, the Bonferroni corrected $p$ values for region by region comparisons of rCBF data showed significant hypoperfusion in selected frontal, temporal, and parietal regions of interest. This apparent contradiction could be explained by the pronounced diffuse reduction of rCBF in the patients with Alzheimer's disease, the high interindividual variability of $\mathrm{rCBF}$ data within each region in healthy subjects, and a possible heterogeneity of severe focal abnormalities in the Alzheimer's disease group. Thus the results of the group comparisons justified the subsequent analysis of individual rCBF data. 
The present study showed that this analysis adds important information in diseases with heterogenous effects on the brain.

PREVIOUS [ $\left.{ }^{99 \mathrm{~m}} \mathrm{Tc}\right]-d, l$-HMPAO STUDIES IN ALZHEIMER'S DISEASE

A number of studies have aimed at characterising the typical perfusion pattern in Alzheimer's disease, by means of SPECT with [99m Tc]- $d, l$-HMPAO.$^{4-12}{ }^{32}$ The most consistent finding seemed to be a significant bilateral reduction of $\mathrm{rCBF}$ in the posterior temporoparietal cortex, in some studies with a meaningful correlation with selected psychometric test results. In only three of the studies $^{6932}$ was a significant reduction of rCBF seen in the frontal lobes as well. In six $^{6-1032}$ the results were supported by parametric data and comparison with control subjects of similar age, but none of these studies had examined individual rCBF patterns by parametric criteria. The heterogeneity of rCBF patterns may have been overlooked in some of these previous reports either because only analysis of group means were performed, or because of variations in the technical quality of the images and in patient selection. In the present study the factorial analysis of variance did not support the idea that the temporoparietal regions were disproportionately affected in Alzheimer's disease. Even conventional region by region group comparisons, as applied in most previous studies, revealed significant rCBF reduction not only in the temporoparietal cortex but also in the frontal association cortex.

\section{HETEROGENEITY OF ICBF PATTERNS IN}

ALZHEIMER'S DISEASE

Alzheimer's disease is not a single entity. The heterogeneity of Alzheimer's disease is shown in many of its aspects: age of onset, duration, clinical course, types and patterns of neurological, psychiatric, and behavioural symptoms, genetic factors, the topography of neuropathological lesions, and response to treatment.

The interpretation of the NINCDSADRDA criteria ${ }^{16}$ may vary considerably from one study to another. This could explain why the accuracy of the clinical diagnosis, as determined by neuropathological criteria, varies from $68 \%{ }^{33}$ to $100 \%,{ }^{34}$ and represents one possible explanation for the discrepancies between the results of previous SPECT and PET reports in Alzheimer's disease. In the present study rigorous inclusion and exclusion criteria were used to select patients with probable Alzheimer's disease. Other studies included patients with periventricular hypodensity on CT, whereas in our present study this finding led to exclusion of the patient. Although Alzheimer's disease may be associated with amyloid angiopathy, which could potentially cause ischaemic degeneration of the periventricular tissue, ${ }^{35}$ periventricular hypodensity on CT may also represent other pathological situations. Because aphasia was initially very prominent in one of the two patients who was diagnosed as having possible
Alzheimer's disease at the time of the study, this patient might have had progressive aphasia with non-Alzheimer pathology ${ }^{3637}$ or focal cerebrovascular disease. At clinical follow up, however, two years later this patient had developed other cognitive deficits and now fulfilled all the criteria for probable Alzheimer's disease. Selection criteria equivalent to those in the present study were used in a recent clinicopathological report in which a $100 \%$ specificity of the clinical NINCDSADRDA criteria was found. ${ }^{34}$ Thus although histopathological confirmation is crucial to the diagnosis of Alzheimer's disease, we would expect the accuracy of our clinical diagnosis to be very high. Therefore, the heterogeneity of rCBF patterns must reflect a heterogeneity of Alzheimer's disease rather than a heterogeneity of diagnoses.

Reduction of rCBF in the frontal lobe was seen more often than expected from the clinical picture of the patients. It has been suggested that frontal hypometabolism relates to severity of dementia. ${ }^{38}$ In our study patients with frontal hypoperfusion did not have a longer duration of disease or a lower MMS score than those without, and there was no significant correlation between frontal rCBF and the MMS scores although it is possible that more extensive cognitive tests would have revealed a significant correlation. No patient presented with severe depression or frontal type behavioural symptoms suggesting a pure frontal lobe dementia, such as Pick's disease. Severe frontal hypoperfusion was seen even in the patient in whom the diagnosis of Alzheimer's disease was later confirmed by neuropathological examination (fig 4). Frontal changes was found in previous PET studies $^{13-1538}$ as well as in sporadic reports on SPECT with [99m Tc]-d,l-HMPAO. ${ }^{6}{ }^{9}{ }^{32}$ Perfusion deficits outside the temporoparietal cortex in patients with a clinical diagnosis of early Alzheimer's disease were also described by Holman et $a l^{39}$ in a recent $\left[{ }^{99 \mathrm{~m}} \mathrm{Tc}\right]-d, l-$ HMPAO SPECT study of patients with memory disturbances and cognitive abnormalities who were prospectively followed up for a final clinical diagnosis. Therefore, bilateral posterior hypoperfusion must not be regarded as the only criterion to diagnose Alzheimer's disease.

Only 13 patients had abnormal rCBF in the hippocampus, a region in which neuropathological and neurochemical changes are seen even in the early phase of the disease. Because of the proximity to cranial bone, however, partial volume effect, and the small size of the region compared with the spatial resolution, the determination of rCBF in the hippocampus region was associated with errors.

Although global CBF correlated significantly with the total cortical atrophy score on CT, there was no evidence that the focal and often asymmetrical reductions in rCBF were associated with severe focal atrophy. Even patients with no atrophy on CT had abnormal [99m $\mathrm{Tc}]-d, l$-HMPAO distribution images. Therefore, the heterogeneity of the rCBF patterns could not be explained by incidental 
focal pathology on CT. Thus the limited spatial resolution and the resulting partial volume phenomenon are not the causes of the focal reductions in cerebral blood flow seen in Alzheimer's disease. The hypoperfusion must reflect a reduced metabolism per $\mathrm{g}$ of brain tissue.

At postmortem examination neuritic plaques and neurofibrillar tangles are distributed quite evenly in the frontal and temporal neocortex and in the hippocampus. ${ }^{33} 3440$ There is a pronounced loss of neurons in frontal as well as temporal regions. ${ }^{41}$ Heterogeneity of the topography of cortical neuropathological changes and of neurotransmitter deficiency during the course of disease progression represents one possible explanation for the heterogeneity of rCBF patterns. Deafferentation from pathologically changed regions of central white matter could also contribute to the heterogeneity of cortical rCBF deficits. In a neuropathological study Brun et $a l^{35}$ found changes in white matter in $60 \%$ of patients with Alzheimer's disease, and a heterogeneity of white matter lesions in Alzheimer's disease shown by MRI has recently been reported. ${ }^{42}$ There are still controversies, however, concerning the hypothetical association of white matter pathology with Alzheimer's disease, and it is not known to what extent this may affect the topography of cortical hypoperfusion.

This study provided evidence that the heterogeneity of rCBF patterns may in part reflect different stages of the disease. The number of affected regions (out of four possible) in the rCBF patterns correlated significantly with the duration of disease. This implies that patients initially develop rCBF reduction primarily in one of the four brain regions, and that during the course of progression, adjacent regions are becoming involved (fig 2). This hypothesis was further supported by the fact that in patients with triad shaped rCBF patterns, the reduction of rCBF was most pronounced in the intermediate of the three regions. There was no relation between the duration of disease and the laterality of the patterns or the presence of frontal rCBF reduction. The heterogeneity of these two aspects probably reflects different behavioural and cognitive subtypes of Alzheimer's disease.$^{14}$ Longitudinal studies with the inclusion of preclinical cases will be necessary to clarify to what extent the heterogeneity of rCBF patterns can be attributed to stages of the disease or to disease subtypes.

We conclude that Alzheimer's disease is associated with heterogenous patterns of focal neocortical rCBF reductions as measured with SPECT and [ $\left.{ }^{99 \mathrm{~m}} \mathrm{Tc}\right]-d, l-\mathrm{HMPAO}$. Hypoperfusion in the frontal cortex was seen more often than previously reported, and no single Alzheimer's disease pattern could be derived from our data. Cortical atrophy could not explain the heterogeneity of rCBF patterns that was partly related to the duration of disease. An analysis of individual rCBF data as performed in the present study, adds important information in the investigation of diseases with heterogeneous effects on the brain.

This study was supported by grants from the Danish Medical Research Council, the Lundbeck Foundation, and the Danish Heart Association. Gerda Thomsen, Glenna Skouboe, and Pia Tejmer are gratefully thanked for their technical assistance.

1 Neirinckx RD, Canning LR, Piper IM, et al. Technetium$99 \mathrm{~m} d, l$-HM-PAO: A new radio-pharmaceutical for SPECT imaging of regional cerebral blood perfusion. 千 Nucl Med 1987;28:191-202.

2 Lassen NA, Andersen AR, Friberg L, Paulson OB. The retention of $\left[{ }^{99 \mathrm{~m}} \mathrm{Tc}\right]-d, l$-HMPAO in the human brain retention of [ after intracarotid bolus injection. A kin

3 Andersen AR, Friberg HH, Schmidt JF, Hasselbalch SG. Quantitative measurements of cerebral blood flow using SPECT and $\left[{ }^{99 \mathrm{~m} T c]}-d, l\right.$-HMPAO compared to xenon133. ₹ Cereb Blood Flow Metab 1988;8:S69-S81.

4 Neary D, Snowden JS, Shields RA, Burjan AWI, Northen B, Macdermott N, Prescott MC, Testa HJ. Single photon emission tomography using $99 \mathrm{~m}$ Tc-HM-PAO in the investigation of dementia. $\mathcal{F}$ Neurol Neurosurg Psychiatry 1987;50:1101-9.

5 Gemmell HG, Sharp PF, Besson JAO, Crawford JR, Ebmeier KP, Davidson J, Smith FW. Differential diagnosis in dementia using the cerebral blood flow agent 99mTc HM-PAO: A SPECT study. $₹$ Comput Assist Tomogr 1987;11:398-402.

6 Perani D, Di Piero V, Vallar G, et al. Technetium-99m HM-PAO-SPECT study of regional cerebral perfusion in early Alzheimer's disease. $\mathcal{F}$ Nucl Med 1988;29: 1507-14.

7 Burns A, Philpot MP, Costa DC, Ell PJ, Levy R. The investigation of Alzheimer's disease with single photon emission tomography. $f$ Neurol Neurosurg Psychiatry 1989;52:248-53.

8 Hunter R, McLuskie R, Wyper D, et al. The pattern of function-related regional cerebral blood flow investigated by single photon emission tomography with ${ }^{99 m} \mathrm{Tc}$ gated by single photon emission tomography with ${ }^{9} \mathrm{Tc}-$ and Korsakoff's psychosis. Psychol Med 1989;19: and K47-55.

9 Montaldi D, Brooks DN, McColl JH, et al. Measurements of regional cerebral blood flow and cognitive performance in Alzheimer's disease. $f$ Neurol Neurosurg Psychiatry 1990;53:33-8.

10 Geaney DP, Soper N, Shepstone BJ, Cowen PJ. Effect of central cholinergic stimulation on regional cerebral blood flow in Alzheimer disease. Lancet 1990;335: 1484-7.

11 Kuwabara $\mathrm{Y}$, Ichiya $\mathrm{Y}$, Otsuka $\mathrm{M}$, et al. Comparison of I-123 IMP and Tc-99m HMPAO SPECT studies with PET in dementia. Ann Nucl Med 1990;4:75-82.

12 Frlich L, Eilles C, Ihl R, Maurer K, Lanczik M. Stagedependent reductions of regional cerebral blood flow meendent reductions of regional cerebral blood flow Alzheimer type. Psychiatry Res 1989;29:347-50.

13 Haxby JV, Duara R, Grady CL, Cutler NR, Rapoport SI. Relation between neuropsychological and cerebral metabolic asymmetries in early Alzheimer's disease. $₹$ Cereb bolic asymmetries in early Alzheim
Blood Flow Metab 1985;5:193-200.

14 Martin A, Brouwers P, Lalonde F, et al. Towards a behavioral typology of Alzheimer's patients. $尹$ Clin Exp Neuropsychol 1986;8:594-610.

15 Haxby JV, Grady CL, Koss E, et al. Heterogenous anterior-posterior metabolic patterns in dementia of the Alzheimer type. Neurology 1988;38:1853-63.

16 McKhann G, Drachman D, Folstein M, Katzman R, Price D, Stadlan EM. Clinical diagnosis of Alzheimer's disease: report of the NINCDS-ADRDA Work Group under the auspices of Department of Health and Human Services Task Force on Alzheimer's Disease. Neurology 1984;34:939-44.

17 American Psychiatric Association. Diagnostic and statistical manual of mental disorders. 3rd ed-revised. DSM-III-R Washington, DC: American Psychiatric Association, Washing
1987.

18 Folstein MF, Folstein SE, McHugh PR. "Mini-Mental State". A practical method for grading the cognitive state
of patients for the clinician. $₹$ Psychiatr Res 1975;12: of patients

19 Blessed G, Tomlinson BE, Roth $M$. The association between quantitative measures of dementia and of senile change in the cerebral grey matter of elderly subjects. $B r$ f Psychiatry 1968;114:797-811.

20 Reisberg B, Ferris SH, de Leon MJ, Crook T. The global deterioration scale for assessment of primary degenerative dementia. Am F Psychiatry 1982;139:1136-9.

21 Hamilton M. Development of a rating scale for primary depression illness. Br 7 Soc Clin Psychol 1967;6:278-96.

22 Waldemar G, Hasselbalch SG, Andersen AR, Delecluse F Petersen P, Johnsen A, Paulson OB. [99mTc]-d,lHMPAO and SPECT of the brain in normal aging. f Cereb Blood Flow Metab 1991;11:508-21.

23 Jacoby RJ, Levy R, Dawson JM. Computed tomography in the elderly: I. The normal population. $\operatorname{Br} \mathcal{F}$ Psychiatry 1980;136:249-55. 
24 Evans WA. An encephalographic ratio for estimating ventricular enlargement and cerebral atrophy. Arch Neurol tricular enlarge

25 Stokely EM, Sveinsdottir E, Lassen NA, Rommer P. A single photon dynamic computer assisted tomograph (DCAT) for imaging brain function in multiple cross sections. F Comput Assist Tomogr 1980;4:230-40.

26 Celsis P, Goldman T, Henriksen L, Lassen NA. A method for calculating regional cerebral blood flow from emission computed tomography of inert gas concentrations. 7 Comput Assist Tomogr 1981;5:641-5.

27 Aquilonius S-M, Eckernäs S- $\AA$. A colour atlas of the human brain. Adapted to computed tomography. Stockholm: brain. Adapted to comp

28 Braak H, Braak E, Bohl J, Lang W. Alzheimer's disease: amyloid plaques in the cerebellum. F Neurol Sci 1989;

29 Brun A, Gustafson L. Distribution of cerebral degeneration in Alzheimer's disease. A clinico-pathological study. Arch Psychiatry Neurol Sci 1976;223:15-33.

30 Klinger A, de Leon MJ, George AE, Miller JD, Wolf AP. Elevated cerebellar glucose metabolism in microvascular white matter disease: normal aging and Alzheimer's disease. 7 Cereb Blood Flow Metab 1988;8:433-5.

31 Akiyama $\mathrm{H}$, Harrop R, McGeer PL, Peppard R, McGeer EG. Crossed cerebellar and uncrossed basal ganglia and

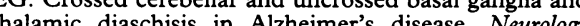
1989;39:541-8.

32 O'Brien JT, Eagger S, Syed GMS, Sahakian BJ, Levy R. A study of regional cerebral blood flow and cognitive performance in Alzheimer's disease. $\mathcal{F}$ Neurol Neurosurg formance in Alzheimer's

33 Risse SC, Raskind MA, Nochlin D, Sumi SM, Lampe TH, Bird TD, Cubberley L, Peskind ER. Neuropathological findings in patients with clinical diagnoses of probable Alzheimer's disease. Am $\mathcal{F}$ Psychiatry 1990; 147:168-72.

34 Morris JC, McKeel DW, Fulling K, Torack RM, Berg L. Validation of clinical diagnostic criteria for Alzheimer's disease. Ann Neurol 1988;24:17-22.

35 Brun A, Englund E. A white matter disorder in dementia of the Alzheimer type: A pathoanatomical study. An Neurol 1986;19:253-62.

36 Mesulam MM. Slowly progressive aphasia without generalized dementia. Ann Neurol 1982;11:592-8.

37 Delecluse F, Andersen AR, Waldemar G, et al. Cerebral blood flow in progressive aphasia without dementia. A case report using 133 xenon inhalation, technetium $99 \mathrm{~m}$ hexamethyl-propyleneamine oxime and single photon emission computerized tomography. Brain 1990;113: emission

38 Frackowiak RSJ, Pozzilli C, Legg NJ, et al. Regional cerebral oxygen supply and utilization in dementia. A clinical and physiological study with oxygen-15 and positron tomography. Brain 1981;104:753-78.

39 Holman BL, Johnson KA, Gerada B, Carvalho PA, Satlin A. The scintigraphic appearance of Alzheimer's disease: prospective study using Technetium-99m-HMPAO SPECT. F Nucl Med 1992;33:181-5.

40 Tomlinson BE, Blessed G, Roth $M$. Observations on the brains of demented old people. F Neurol Sci 1970;11: 205-42.

41 Terry RD, Peck A, DeTeresa R, Schechter R, Horoupian DS. Some morphometric aspects of the brain in senile dementia of the Alzheimer type. Ann Neurol 1981; dementia

42 Scheltens $\mathrm{P}$, Barkhof F, Valk J, et al. White matter lesions on magnetic resonance imaging in clinically diagnosed Alzheimer's disease. Evidence for heterogeneity. Brain 1992;115:735-48 